OBSTETRICS FOR STUDENTS 
BY THE SAME AUTHOR

Gynaecology for Students

High Blood Pressure and Pregnancy 


\section{OBSTETRICS \\ FOR STUDENTS}

THIRD EDITION

\section{LANCE TOWNSEND}

Kt., V.R.D., M.D., B.S., D.T.M. \& H., F.R.C.S. (Edin.),

F.A.C.S., F.R.A.C.S., F.R.C.O.G., Hon. F.R.C.S. (C), Hon. F.A.C.O.G., Hon. F.C.O.G. (S.A.)

Professor Emeritus of Obstetrics and Gynaecology

University of Melbourne 
(C) 1964, 1969, 1978 Sydney Lance Townsend

Softcover reprint of the hardcover 3rd edition 1978 978-0-333-23015-2

All rights reserved

No part of this publication

may be reproduced or transmitted

in any form or by any means

without permission

First published 1964

Second edition 1969

Third edition first published 1978 by

THE MACMILLAN COMPANY OF AUSTRALIA PTY LTD

107 Moray Street, South Melbourne 3205 and

12 Berry Street, North Sydney 2060

Associated companies in

London and Basingstoke, England

New York Dublin Johannesburg Delhi

National Library of Australia

cataloguing in publication data

Townsend, Sydney Lance, 1912

Obstetrics for students.

Index.

ISBN 978-1-349-03533-5 ISBN 978-1-349-03531-1 (eBook)

DOI 10.1007/978-1-349-03531-1

1. Obstetrics. I. Title.

618.2 


\section{ONTENTS}

PREFACES

INTRODUCTION

1 THE OVUM AND ITS FERTILIZATION 2

The Physiology and Development of the Ovum-The PlacentaLiquor Amnii

2 THE PHYSIOLOGY OF THE PLACENTA AND FOETUS

Placental transfer--Immunological Response-Placental Hormones -Development of the Foetus-Foetal Physiology

3 THE PHYSIOLOGY OF PREGNANCY

Metabolic Changes during Pregnancy-Changes in the Genital Organs-Other Changes

4 THE DIAGNOSIS OF PREGNANCY

5 OBSTETRIC EXAMINATION

Diagnosis of Lie, Presentation and Position of Foetus

6 ANTE-NATAL CARE

General Procedure-Drug Therapy in Pregnancy-Common Complaints in Pregnancy

7 NORMAL LABOUR

Causation of Labour-The Stages of Labour-The Powers-The Passages-The Passengers

8 THE MECHANISM OF LABOUR IN VERTEX PRESENTATIONS IN THE OCCIPITO-TRANSVERSE POSITION

Mechanism in the Left or Right Occipito-Transverse PositionEffects of Labour on the Foetal Head

9 NORMAL LABOUR: COURSE AND MANAGEMENT

Changes in Late Pregnancy-Recognition of the Onset of Labour -Admission to Hospital-Course and Management of the First Stage of Labour-Course and Management of the Second Stage of Labour-Course and Management of the Third Stage of Labour-Psychological Approach to Labour-Anaesthetic and Analgesic Agents used in Obstetrics-Self-administered Inhalational Analgesia-Regional Analgesia-Uterine Stimulants 
Physiology of the Puerperium-Management of the PuerperiumMinor Abnormalities and Conditions found in the PuerperiumPost-Natal Check

DISEASES AND ABNORMALITIES OF THE SECUNDINES

Diseases of the Chorion-Diseases of the Amnion-Abnormalities and Diseases of the Placenta-Anomalies of the Umbilical Cord

Anaemia-Pyelonephritis-Pulmonary Tuberculosis-Cardiac Disease-Glycosuria during Pregnancy-Diabetes Mellitus-Thyroid Disease-Venereal Diseases-Rubella-Jaundice in PregnancyAnterior Poliomyelitis-Influenza-Pneumonia-Other Infectious Diseases

Fibromyomata-Ovarian Tumours-Carcinoma of the CervixAppendicitis-Retroversion of the Gravid Uterus-Downward Displacements of the Uterus

ANTE-PARTUM HAEMORRHAGE

Definition-Placenta Praevia--Accidental Haemorrhage (Abruptio Placentae)-Acute Renal Failure and Pregnancy POSITION

Anterior Rotation through $135^{\circ}$ (Complete)-Anterior Rotation through less than $135^{\circ}$ (Incomplete)-No Rotation-Posterior Rotation-Comments on Some Components of the MechanismsTreatment

Face Presentation-Brow Presentation-Transverse Lie and Shoulder Presentation-Compound Presentations-Presentation and Prolapse of the Cord 
21 MULTIPLE PREGNANCY

Twins-Triplets

22 CEPHALO-PELVIC DISPROPORTION

Contracted Pelvis-Pelvic Inlet Contraction

23 THE MECHANISM AND MANAGEMENT OF LABOUR IN DISPROPORTION

Treatment-Trial of Labour-Caesarean Section-Induction of Premature Labour

24 ABNORMAL UTERINE ACTION

Precipitate Labour-Retraction Ring-Generalized Tonic Contraction (Uterine Tetany)-Uterine Inertia-Uterine Exhaustion -Inco-ordinate Uterine Action-Spurious Labour-Cervical Dystocia-Constriction Ring-Prolonged Labour-Obstructed Labour

FAULTS IN THE PASSENGERS

433

Premature Rupture of the Membranes-Post-Maturity-Abnormalities of Foetal Development

INJURIES TO THE BIRTH CANAL

Vulva-Perineum - Vagina-Episiotomy-Cervix-Rupture of the Uterus-Internal Traumatic Haemorrhage-Retroperitoneal Haematoma-Inversion of the Uterus-Fistulae

ABNORMALITIES OF THE THIRD STAGE OF LABOUR AND PUERPERIUM

Primary Post-Partum Haemorrhage-Treatment of Primary PostPartum Haemorrhage--Retained Placenta--Constriction Ring in the Third Stage - Placenta Accreta-Adherent Membranes-Secondary Post-Partum Haemorrhage-Venous Thrombosis-Pulmonary Embolism-Pulmonary Amniotic Fluid Embolism-Shock in Obstetrics-The Causes of Sudden Death during Pregnancy and Puerperium-Bacteraemic Shock

Description of the Disease-Clinical Picture of Puerperal Infection - The Diagnosis of Puerperal Infection-The Prevention of Puerperal Infection-The Treatment of Puerperal Infection-Acute Mastitis

Therapeutic Abortion-Induction of Premature Labour and of Labour 
The Uses of Forceps-Indications for Forceps-Application of Forceps (Neville-Barnes)-Failed Forceps

32 THE VACUUM EXTRACTOR (VENTOUSE)

Description-Indications-Contra-indications

33 VERSION

External Cephalic Version-External Podalic Version-Internal Version-Bipolar Version (Braxton-Hicks)

34 DESTRUCTIVE OPERATIONS

Craniotomy-Embryotomy

35 CAESAREAN SECTION

The Types of Operation

THE NEWBORN INFANT by W. H. Kitchen

36 ASPHYXIA

583

37 ROUTINE CARE OF THE NEWBORN INFANT

38 FEEDING THE INFANT

603

Breast Feeding-Artificial Feeding of the Normal Infant

39 INJURIES DURING BIRTH

40 MALFORMATIONS

41 OTHER DISORDERS OF THE NEWBORN

Vomiting-Diarrhoea-Constipation-Abnormal Cardiac Conditions-Abnormalities of the Genital System--Abnormalities of the Renal Tract-Skin Conditions-Congenital Conditions Associated with Mental Defect

42 JAUNDICE IN THE NEWBORN

43 RESPIRATORY DISORDERS OF THE NEWBORN

44 HAEMATOLOGICAL CONDITIONS OF THE NEWBORN

45 IMMATURE AND LOW BIRTH WEIGHT INFANTS 
47 CARE OF INFANTS BORN IN SPECIAL CIRCUMSTANCES 716

48 PERINATAL MORTALITY by Lance Townsend 721

$\begin{array}{ll}\text { INDEX } & 727\end{array}$ 


\section{PREFACE TO THIRD EDITION}

The pleasure that the preparation of the third edition of this book has given me in the evening of my academic career has amazed me. Looking forward from the time when the book was first published fourteen years ago I imagined then that when I was preparing the third edition there would be little to alter.

The advances in obstetric practice continue, and at such a rate that most of the book has needed some revision. The chapters on Radiology and Puerperal Infection have been revised so that the whole of the obstetric text has been written by myself. Dr W. H. Kitchen has revised the Paediatric section, which has always been regarded as superior to the Obstetric section.

I have again received help from many sources. Dr J. H. Evans has again read the manuscript and proofs and supervised the final format of the book. Dr James Smibert went through the second edition very carefully and made many suggested alterations which have been included. Dr Kevin McCaul has contributed the section on Pain in Labour and Dr R. Pepperell has also assisted with the preparation of some sections. Mrs A. Sultzer, Department of Pathology, Royal Women's Hospital has made some new line drawings. Miss Muriel Ryan and Miss Lorraine Morrison have done the typing and arranged the alterations in the old manuscript. Members of the Professorial Unit, Royal Women's Hospital have given me assistance with minor details.

I wish to thank The Macmillan Company of Australia for publishing this edition. Mr Brian Stonier and Mr John Rolfe have been of great assistance in the efficient and speedy manner with which the book has been published.

\section{PREFACE TO SECOND EDITION}

The preparation of the second edition of this book has brought home to me the many advances that have occurred in obstetrics and neonatal paediatrics in the last five years.

The reception of the first edition has encouraged me to prepare this second edition which I hope will be as well received. Dr Kate Campbell has now retired from my department as Neonatal Paediatrician, and the neonatal section, which continues to be a major portion of the book, has been completely rewritten by her successor, Dr W. H. Kitchen.

I have again received help from many sources. Dr J. H. Evans has read the manuscript and proofs and supervised the final format of the book. Dr Kevin Collins has given me many helpful suggestions regarding minutiae which he noted whilst an undergraduate. Miss Gillian Haag, Department of Pathology, Royal Women's Hospital, has modified some of the illustrations and Miss M. Smith has prepared some of the diagrams. Miss Muriel Ryan, my secretary, has done all the typing and arranged the alterations in the old manuscript.

Now that the work is complete it has been a rewarding task and I thank the above-mentioned and all my staff for direct and indirect assist- 
ance during the preparation of the book. The staff of the Melbourne University Press has again been co-operative in the preparation of this edition.

\section{PREFACE TO FIRST EDITION}

This textbook of obstetrics is a companion volume to Gynaecology for Students, published in 1961. For a considerable time it has been the practice in the University of Melbourne for successive lecturers in Obstetrics and Gynaecology to supply the undergraduates with printed notes. The first of these were produced in 1926 by the late Dr Arthur Wilson, and there were several revisions by the late Professor R. Marshall Allan, first and only Professor of Obstetrics in the University of Melbourne; they were again revised in 1949 by $\mathrm{Dr}$ J. W. Johnstone whilst he was ActingProfessor. In 1955 I undertook a further revision of the sections on obstetrics during a visit to the Johns Hopkins Hospital as the guest of Dr Nicholson J. Eastman. For some years undergraduates have requested that the notes be produced in normal book format, as has been done with the section on gynaecology.

During the production of the present volume I have received the help of many of my colleagues, to whom my gratitude is extended. Dr Kate Campbell has written the section on neo-natal paediatrics which constitutes a major contribution to the book. Dr A. M. Hill is responsible for the chapter on puerperal infection and portion of the chapter on abortion, and Dr Colin Macdonald for the chapter on radiology in pregnancy.

Dr Kevin McCaul has corrected and rewritten most of the section on analgesia and anaesthesia in obstetrics; Dr Frank Forster has written the section on liver disease in pregnancy, and Dr James Smibert has read and made suggestions concerning the chapters dealing with pre-eclampsia and medical diseases in pregnancy. Dr Hans Bettinger has made available from his department at the Royal Women's Hospital the photomicrographs and clinical photographs.

Dr John Nattrass has read the manuscript and proofs and made many valuable suggestions and corrections in the subject matter and in the final wording of the text. He has also compiled the index. Dr Eric Mackay assisted with the manuscript in the previous edition of the notes. Dr Norman Beischer has prepared the captions to the illustrations, selected the clinical photographs for reproduction, and assisted in the correction of all parts of the manuscript. Miss L. Kerley, of the Department of Obstetrics and Gynaecology, made the line drawings. Miss M. Johnson, of the Department of Pathology, Royal Women's Hospital, and Mrs M. Pertinac, of the University Department of Obstetrics and Gynaecology, prepared the photographs. Dr Michael Kloss read the manuscript to ensure that our change-over to the metric system was accurate. Miss Muriel Ryan, my secretary, typed 
numerous versions of the text and was assisted by Mrs S. Edwards. Their industry and skill at deciphering largely illegible hand-writing have done much to shorten and lighten the task of preparation.

The present volume embodies the principles and practice of obstetrics) and neonatal paediatrics as taught to undergraduates. It is hoped that medical practitioners also will find the book helpful for reference when they are faced with problems in these fields during the course of practicc.

Its publication marks the centenary of the founding of the Clinical School at the Royal Women's Hospital, in which all medical graduates of the University of Melbourne have received their basic training in obstetrics. I am grateful to the members of the School in general and to my colleagues and friends in particular for the help received in the publication of this book.

L.T. 